
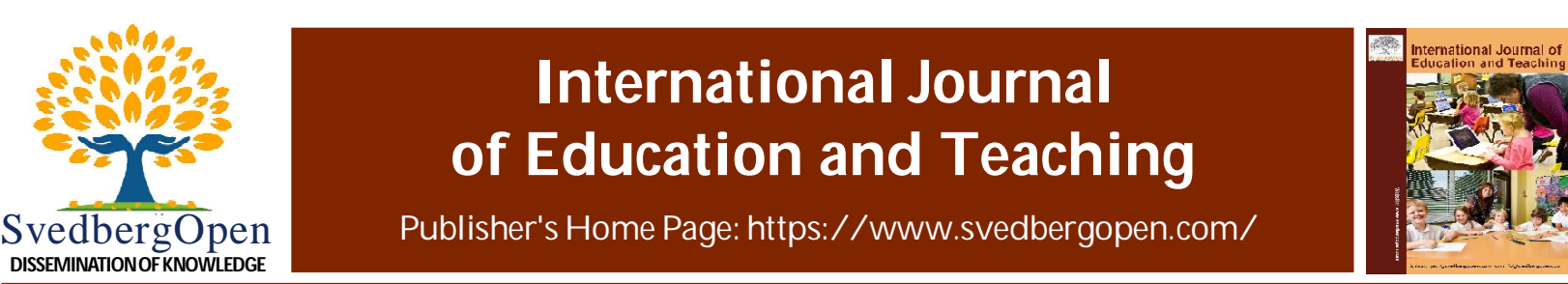

Research Paper

Open A ccess

\title{
Teaching and learning in the new normal: Opportunities and challenges of distance learning amid covid-19 pandemic
}

\author{
Caroline Gurajena $^{1}$, Elliot Mbunge ${ }^{2 *}$ and Stephen G Fashoto ${ }^{3}$ \\ ${ }^{1}$ Department of Computer Science, Faculty of Science and Engineering, University of Eswatini, Kwaluseni, Eswatini, Swaziland. \\ E-mail: gurajenacaroline@gmail.com \\ ${ }^{2}$ Faculty of Science and Engineering, University of Swaziland, Private Bag 4 Kwaluseni, Swaziland. E-mail: mbungeelliot@gmail.com \\ ${ }^{3}$ Department of Computer Science, Faculty of Science and Engineering, University of Eswatini, Kwaluseni, Eswatini, Swaziland. \\ E-mail:sgfashoto@uniswa.sz
}

Article Info

Volume 1, Issue 2, June 2021

Received : 18 January 2021

Accepted : 17 May 2021

Published : 05 June 2021

doi: 10.51483/IJEDT.1.2.2021.9-15

\begin{abstract}
To continue with teaching and learning during the novel coronavirus disease 2019 (Covid19) pandemic, most tertiary institutions have adopted distance learning. The adoption of distance learning is not without its limitations and challenges which includes limited network coverage and lack of gadgets among the students. Due to the Covid-19, we perceived the need to analyze the opportunities and pitfalls of distance education in Africa. This paper reviews the opportunities and pitfalls of integrating emerging technologies for distance learning during the Covid-19 pandemic. Taking into consideration the categories and the barriers; the challenges faced by tertiary institutions can be categorized to include technological challenges, pedagogical challenges and social challenges. Also, distance education encourages student-centered learning and self-learning. It offers a lot of opportunities to tertiary institutions which includes scalability, research innovations, flexible learning, diversity, remote students support, adjustment of assessment methods, innovation opportunity, offer non-academic courses, change of pedagogical policies.
\end{abstract}

Keywords: Distance learning, Covid-19 pandemic, Teaching, Learning

(C) 2021 Caroline Gurajena et al. This is an open access article under the CC BY license (https://creativecommons.org/licenses/by/4.0/), which permits unrestricted use, distribution, and reproduction in any medium, provided you give appropriate credit to the original author(s) and the source, provide a link to the Creative Commons license, and indicate if changes were made.

\section{Introduction}

Telecommunication technologies and the Internet have removed distance and space barriers in communication and interaction. These technologies can also be used in education in many forms which include blended learning and distance learning. Tertiary Institutions (TIs) in Africa have been gradually adopting technology to support teaching and learning through Learning Management Systems (LMSs) such as Moodle and Blackboard (Mbunge et al., 2020c) and also other emerging technologies such as virtual reality (Salyers et al., 2014), education data mining and artificial intelligence tools (Bimha et al., 2021). Students can access and obtain learning resources through the learning platform and lecturers can post-assessment activities on the learning platform. Even with this adoption, officially most African TIs relied on face-to-face teaching methods which are now facing challenges due to the pandemic. To alleviate the spreads of Covid-19, World Health Organization implemented COVID-19 infection control and preventive measures

\footnotetext{
* Corresponding author: Elliot Mbunge, Department of Computer Science, Faculty of Science and Engineering, University of Eswatini, Kwaluseni, Eswatini, Swaziland. Email: gurajenacaroline@gmail.com
} 
such as social distancing (Mbunge, 2020b), quarantine, self-isolation (Mbunge et al., 2020b) and face masking (Siewe Fodjo et al., 2020) among others. Also, regulatory authorities implemented restrict regulations, recursive national lockdowns to minimize movements of people in order to reduce new infections and deaths (Mbunge, 2020a). Several digital technologies have been developed and implemented to enhance these regulations (Mbunge et al., 2020a) and to ensure the safe reopening of schools, colleges and universities as well as industries. However, due to new COVID-19 variant detected (Wise, 2020), many countries announced emergency lockdown, leaving TIs without choice other than to resort to Distance Learning (DL). As a result, most students and lecturers in the less developed regions of Africa were forced to use new technologies and educational resources that they were not familiar with as TIs tried to salvage what was left of the academic (Adedoyin and Soykan, 2020). TIs lost time as they tried to make the necessary plans to move both the learning activities and assessments methods online. This caused a setback in an effective education. According to the United Nations Development Programme (UNDP), the setback in effective education during the COVID-19 pandemic has affected close to 9 in 10 students (UNDP, 2020a). This setback must be addressed to improve the quality of education. This can be achieved by improving addressing the challenges that have been identified in DL and also taking advantage of the opportunities that DL offers.

The main challenge in DL is how emerging technologies can be organized in teaching and learning (Sangrà et al., 2012). When technology is properly integrated into teaching and learning, it offers students the opportunity to communicate with their instructors in near real-time. It also provides a more efficient communication method among the students provides access to various tutorials. The learning that occurs during the use of technology cannot be overlooked. Apart from the actual content of the course being provided through distance education, the students are also exposed to learning skills for using different technologies. This interaction with technology helps the students to prepare for employment in the fourth industrial revolution.

This paper aimed to examine and discuss the challenges and pitfalls of DL. The core focus of this research paper is DL at African TIs during the COVID-19 pandemic. The research highlights the challenges and opportunities of DL in Africa. This paper is structured as follows: section 2 gives a summary of the methodology, the comparison of e-learning and distance education is given in section 3, section 4 reports results of the research, section 5 discusses the recommendations and section 6 concludes the paper.

\section{Research methods and materials}

The aim of this paper is to render the perspective and experience of lecturers' in teaching during the COVID-19 pandemic. This paper is based on the analysis performed through literature review of publications on DL and e-learning as well as the authors' own experience of distance education during the COVID-19 pandemic. The reflection of the authors covers the challenges they encountered and the opportunities they identified. The databases used in the review include ACM, IEEE and Springer. The initial search in the databases focused on DL and e-learning. The second search included the keyword "COVID-19" and "Africa". Most of the articles had publications dates that ranged from 2012 to 2020 except for a few articles which were published earlier. The focus of this research is to highlight the pitfalls and the opportunities for distance education in Africa to offer future guidance to TIs.

\section{E-Learning and DL}

The education sector was forced to change teaching techniques and operation rules overnight (Corlatean, 2020; and Dhawan, 2020). The focus of the education sector shifted from face-to-face teaching method to DL. King et al. (2001) defined DL as "improved capabilities in knowledge and/or behaviors as a result of mediated experiences that are constrained by time and/or distance such that the learner does not share the same situation with what is being learned".

Initially, DL was targeted to full time working students and residents of the geographically remote place who were not able to physically attend TIs. DL proceeded e-learning. E-learning is the result of integrating education and ICTs. DL contributed immensely to the use of ICT for educational purposes (Sangrà et al., 2012). Over the past two decades, DL has become pervasive and reliant on ICTs. With the advancement of technology, DL had migrated to be a type of electronic learning (e-learning). There is no formally agreed-upon definition of e-learning and Sangrà et al., (2012) defined it as " $E$ learning is an approach to teaching and learning, representing all or part of the educational model applied, that is based on the use of electronic media and devices as tools for improving access to training, communication and interaction and that facilitates the adoption of new ways of understanding and developing learning" . E-learning was defined by Salyers et al. (2014) as "an integration of pedagogy, content, and technologies within a teaching and learning context". The definition of e-learning for this research is going to be based on these two definitions. 
E-learning is a result of the merging of multiple disciplines which includes pedagogy, computer science and communication technology. Technologies used in e-learning include LMSs, videoconferencing, web-conferencing, instant messaging and multimedia tools. E-learning can be used for both autonomous learning and individual learning (Mbunge et al., 2020c). E-learning can be considered as the new way of teaching and learning especially in most parts of Africa. E-learning can be regarded as a natural evolution of DL. E-learning is always evolving; taking advantage of new emerging technologies. Lecturers need to understand that e-learning as an educational innovation which must be adapted to meet the changing learning needs of the students. The benefits of e-learning include increased interactivity and collaboration among students which improves the quality of learning. E-learning also provides a flexible and costeffective form of education (Al-Samarraie et al., 2018; and Mohamed Abd El-Hamed Diab and Fouad Elgahsh, 2020). Since DL during the COVID-19 pandemic, the mode of course delivery was done entirely through the Internet, the terms e-learning and distance education were used interchangeably throughout this paper.

\section{Challenges and opportunities of distance education}

Fundamentals of areas of human development including education are declining across many countries (UNDP, 2020b). TIs encountered a variety of challenges in implementing DL during the COVID-19 pandemic. According to Sangrà et al. (2012), e-learning is composed of four main categories: technology, delivery system, communication and educational paradigms. These categories can be used to identify and group the challenges encountered in DL. The barriers to elearning were classified by Mohamed Abd El-Hamed Diab and Fouad Elgahsh (2020) as personal inhibitors, attitudinal inhibitors and contextual inhibitors. Taking into consideration the categories and the barriers, the challenges faced by TIs can be categorized to include technological challenges, pedagogical challenges and social challenges. The following sections are going to expand on each of these challenges.

\subsection{Social challenges}

In addition to affecting the education sector, the COVID-19 pandemic also affected societies and economies (UNDP, 2020b). One of the challenges in distance education in Africa is the digital divide exacerbated by poor economic conditions. The COVID-19 pandemic has magnified the digital divide in most African countries. TIs had to come with ways to cater for students who were affected by the digital divide. The exclusion and inequality caused by the digital divide need to be addressed to ensure that all students have equal access to educational materials.

Socioeconomic factors have to be taken into consideration as well in distance education. COVID-19 also affected humanity in terms of socioeconomic (Corlatean, 2020). Even with the decline of the cost of hardware, telecommunication and software, students from low-income families have challenges getting access to e-learning services. Due to the lockdown, the economies of most African countries suffered and this resulted in the loss of jobs, especially in middleand low-income class. Students from such families were able to either afford to buy the necessary digital devices requires for DL or the students were not able to afford to buy the data they needed to access online resources.

\subsection{Technological challenges}

Distance education offers learning opportunities which are not restricted by geographical locations. However, in the African context, these opportunities may be hindered by many factors which include:

a. Lack of telecommunication services: In some marginalized area, DL resources proved to be inaccessible to students due to factors such as lack on network coverage and in some cases, students lacked devices to access the Internet. This is a problem, especially in marginalized rural areas. During the lockdown, students had access to their institutions and learning resources through the Internet. This proved to be impossible for students that stay in marginalized rural areas. Students from less developed regions were most affected by the pandemic (Corlatean, 2020).

b. Internet connectivity problems: Some students are faced with a lack of Internet access due to digital divide (Mishra et al., 2020), high cost of internet data bundles (Adedoyin and Soykan, 2020), weak network signals and poor network coverage (Ogunleye et al., 2018).

c. Lack of digital skills: One of the main challenges faced by institutions in implementing distance education is lack understanding and skills for using online resources by both students and teachers. Lack of training and attitude towards using technology may also hinder the effectiveness of the virtual learning environment (Mishra et al., 2020). Some lecturers were not prepared to teach online courses because of insufficient training and unfamiliarity with technology such as video recording and editing software. Lecturers require formal training on how to effectively use technology in DL. Technology on its own does not improve the learning process of students. Lecturers need to be creative when designing online course materials and they also need to be well informed about the available technology. 
d. Poor DL infrastructure: TIs were not prepared to offer electronic resources for teaching and learning to all the enrolled students. The technological issues such as unreliable access to LMS especially during peak hours as more users tried to access the servers where the LMS was hosted than what the servers could handle. This lead to a lack of server access due to the maximum number of concurrent connections being exceeded. Lack of required technological equipment for conducting online classes also hindered lecturers.

e. Unreliable internet services: Erratic Internet services affect the availability of online resources. Lectures were also faced with poor Internet services which included low bandwidth and service interruption. This hindered lecturers in delivering lectures through though videoconferencing.

f. Load shedding: Lack of consistent power supply due to load shedding also affects DL.

g. Inadequate support services: Lack of institutional support in the use of learning techniques can also affect the use of e-learning resources by students (Mohamed Abd El-Hamed Diab and Fouad Elgahsh, 2020).

For DL to be successful, there is a need to ensure that all student and lecturers have access to the technologies that are required in online teaching and learning. Unequal access to technology is having a significant impact on DL. The ability to have access to technology is determined by the availability of telecommunication services and household means to provide the required gadgets. To address the lack of skills and training among lecturers, institutions need to conduct intensive training on creating online materials and effective use of different technologies in delivering online classes.

\subsection{Pedagogical challenges}

One of the challenges encountered in distance education is the lack of necessary knowledge and skills on how to conduct online classes. In order to create an effective environment, lecturers need to be extensively trained on how to adapt their teaching methods to suit DL and how to utilize technology (Valentine, 2002). Lack of effective teaching practices and communication patterns affect DL students (Markova et al., 2016). In order to address this challenge, institutions and lecturers need to be committed and forward-thinking. There is need for lecturers to understand the needs of the student before designing course material. This knowledge will assist the lecturers in creating an effective learning environment. Markova et al. (2016) highlighted that the "quality of students' knowledge will depend on the improved instruction and new methods of teaching rather than on replication of traditional methods". Lectures need to be committed to designing course materials that are student-centered which incorporates learning principles in technology-mediated environments. The design and delivery of teaching material should be suitable to achieve the objectives of the course. TIs also need to acknowledge that in some instances online assessment methods are not sufficient for measuring the learning outcomes.

\section{Opportunities}

Distance education encourages student-centered learning and self-learning. It offers a lot of opportunities to TIs which includes:

a. Scalability: Expanding the programs and intake is possible with DL. The pandemic provided an opportunity for most African TIs to recognize the possibility of expanding through DL.

b. Flexible learning: DL offers flexible learning to students which can meet the different needs of the diverse range of students. It enables the students to choose when and how they want to learn. Through access to the learning platform, the students have communication with their lecturers. This enables the students to handle their schoolwork and social life. The flexibility in DL includes teaching modes, assessments types and learning times. The flexibility offered the students the opportunity to learn and work. The flexibility of the courses in terms of time was still restricted with the tertiary institution's calendar.

c. Diversity: TIs can cater for students with diverse profiles. Distance education offers the TIs the opportunity to reach and cater for the large number of students in various locations.

d. Student support: Online environment provides new support opportunities for students and enables TIs to catch up with the changing time of the digital era to meet the demand of the students. Online learning provides new forms of interaction and learner support. It also provides new methods of assessment for lecturers.

e. Assessment methods: LMSs provides various assessments methods which can be used by lecturers to instigate a grasp of the knowledge being communicated to the students. Frequent and different kinds of assessments also encourage the students to allocate more time for in-depth studying. Also, online assessments platforms should be secured and authenticate students before writing an assessment (Elliot and Talent, 2018). 
f. Innovation opportunity: DL in Africa provides the opportunity to create innovative teaching and learning solutions that are suitable for the African context. Such solutions should focus on maximizing learning using available technologies. Provision of low data consumptions and transmission mobile applications will help students with financial challenges.

g. Non-academic courses: DL provides TIs with the opportunity to offer non-academic courses which can benefit both academic students and non-academic students. This can help students to develop additional skills.

\section{Discussion}

During the COVID-19, African TIs were left with no other choice than to adopt DL in order to continue with academic activities during the lockdown. E-learning goes just using technology; it focuses on the actual learning that the students are exposed to using the technology. This means both students and lecturers have to be efficient in using the technology that is being employed in e-learning so that the focus can be on the actual course content.

As society evolves, there is a need for education to evolve as well. According to UNESCO (2003), learning occurs at both individual and social level. Sangrà et al. (2012) also emphasized the importance of socialization in DL. Social context can be used to support the self-regulation learning process (Kocdar et al., 2018). Social interactions and collaborations among students are important. Such activities help students to exercise teamwork. E-learning provides more interaction options compared to face-to-face learning (Bouhnik and Marcus, 2006). Interactions can be promoted through integrating discussions in the learning platforms. It is essential to ensure that the technologies being used in DL promote interaction among students and lecturers. It is important to keep open-communication line between students and lecturers. As DL is student-centered, communication and interaction should also be student centered in order to encourage participation of the students. The use of group-based assessments can be used to encourage communication and interaction among students. Student-centered learning requires student to be self-regulated. Without self-regulation, students have difficulty in in managing their learning process (Kocdar et al., 2018).

The way the learning outcomes and the content are presented can have effects on student's learning. The design of online instructional material and the delivery of the material is pivotal in creating virtual learning environments that effective (Markova et al., 2016). Design expertise and delivery skills are crucial in virtual environments (Salyers et al., 2014). Both students and lecturers need to understand online education and the patterns of online learning for DL to be successful. Treating online education like face-to-face education will frustrate and burden the students. The way the instructional content is delivered has to cater for all students. In order to create effective instruction material; all stakeholders such as instructional designers, subject experts, educational technology specialists, should be involved. The technical abilities and experiences of students should be considered when designing the course materials and the assessments. Institutional standards for course material design may be used in order to standardize the virtual environment for all courses. This will make it easier for students to quickly become familiar and comfortable with the technologies being used. TIs should also implement policies for online learning and assessment. One of the issues that need to be addressed in the policies is how to measure and ensure the quality and effectiveness of DL. E-learning environments should (Salyers et al., 2014):

- address the needs of diverse learners,

- apply suitable pedagogical strategies,

- incorporate instructional design principles suitable for e-learning,

- $\quad$ support different kind of technologies, and

- support flexible and interactive learning opportunities that meet the needs of the students

Technical support is very essential in DL. Having an efficiently working environment will prevent the students and lecturer from being anxious and frustrated (Markova et al., 2016; and Mashwama et al., 2020). In addition to training lecturers, students also need training on the effective use of the available technologies. DL enables students to learn to their own pace and this can significantly reduce the time required by the students to learn.

\section{Conclusion}

Nowadays the use of mobile devices and computers is an integral part of our lives. Over the past couple of years, the use of the Internet in communicating has been viewed as a form of efficient means of interaction among people. The Internet provides a similar interactive environment through e-learning and DL. In order to salvage what was remaining of the 
year, TIs adopted DL so that students would not lose the whole academic year. The research shows that distancing learning is promising in implemented cautiously. The online learning provides more effective methods of communication for both the lecturers and students. However, it should be noted that the effectiveness of the communication methods also depends on the feedback that the students and the lecturers provide.

The effectiveness of DL depends on how the courses are designed and how students supported. All the online activities have to be designed in such a way that they support the student in grasping the course content. It is essential to have clearly defined effective interaction between lecturers and students in order for DL to be effective. Most students are acquainted with technology; especially technology used in social media. Students with access to technology are technologically sophisticated and appreciate integrating technology into their learning activities. Online courses should be tailored to meet the needs of students. Technology can be effectively used to teach students. Effective virtual learning environments can be created by adapting traditional teaching methods the suit distance education. As distance education is student-centered, it important for students to understand their responsibility and to be disciplined. DL offers flexibility to students that cannot be overlooked. It is important to clearly define how best to integrate e-learning technologies into the curricula taking into consideration the challenges encountered by students.

DL can be hindered by a lack of ICT skills among both students and lecturers. For effective DL, TIs need to invest in resources that support e-learning activities. Also, financial support from governments in developing DLinfrastructure and provision of electronic resources would aid in the implementation and maintenance of DL (Mbunge, 2018). The pandemic provided TIs with an opportunity to explore the possibility of e-learning and blended learning. This opportunity can also alter the perceptions of both students and lecturers towards e-learning and possibly reduce resistance, which can lead to social unrests in higher institutions (Onyema et al., 2020; Elliot et al., 2017; and Mbunge et al., 2021). There is still a need to investigate the effects of DL among students during the COVID-19 pandemic.

\section{References}

Adedoyin, O.B. and Soykan, E. (2020). Covid-19 pandemic and online learning: the challenges and opportunities. Interactive Learning Environments. doi: 10.1080/10494820.2020.1813180

Al-Samarraie, H., Teng, B.K., Alzahrani, A.I. and Alalwan, N. (2018). E-learning continuance satisfaction in higher education: a unified perspective from instructors and students. Stud. High. Educ., 43(11), 2003-2019. doi: 10.1080/ 03075079.2017.1298088

Bimha, H., Mbunge, E. and Fashoto, S. (2021). Prediction of box-office success: A review of trends and machine learning computational models. Int. J. Bus. Intell. Data Min. doi: 10.1504/ijbidm.2021.10032162

Bouhnik, D. and Marcus, T. (2006). Interaction in distance-learning courses. J. Am. Soc. Inf. Sci. Technol. 57(3), $299-305$. doi: 10.1002/asi.

Corlatean, T. (2020). Risks, discrimination and opportunities for education during the times of COVID-19 pandemic. in Proceedings of the 17th Research Association for Interdisciplinary Studies. 37-46, doi: 10.5281/zenodo.3909867

Dhawan, S. (2020). Online learning: A panacea in the time of covid-19 crisis. J. Educ. Technol. Syst. doi: 10.1177/ 0047239520934018

Elliot, M. and Talent, K. (2018). A robust and scalable four factor authentication architecture to enhance security for mobile online transaction. Int. J. Sci. Technol. Res. 7(3), 139-143.

Elliot, M., Fanwell, V. and Kinsley, K. (2017). A tool to predict the possibility of social unrest using sentiments analysis - case of zimbabwe politics 2017-2018. Int. J. Sci. Res. .

King, F., Young, M., Richmond, K., Schrader, P.G. and Kelly, (2020). Defining distance learning and distance education. Educ. Technol. Rev. 9, 2001.

Kocdar, S., Karadeniz, A., Bozkurt, A. and Buyuk, K. (2018). Measuring self-regulation in self-paced open and distance learning environments. Int. Rev. Res. Open Distrib. Learn. 19(1), 24-43. doi: https://doi.org/10.19173/irrodl.v19i1.3255

Markova, T., Glazkova, I. and Zaborova, E. (2016). Quality issues of online distance learning. in 7th International Conference on Intercultural Education "Education, Health and ICT for a Transcultural World". 685-691. doi: 10.1016/j.sbspro.2017.02.043.

Mashwama, P., Fashoto, S.G., Mbunge, E. and Gwebu, S. (2020). Development of a mobile inter-vehicular communication system based on gossip algorithm. Int. J. Interact. Mob. Technol., 14(11), doi: 10.3991/ijim.v14i11.12949 
Mbunge, E. (2018). Adoption of smart grid framework which tracks power consumption of household appliances in Zimbabwe. Am. J. Oper. Manag. Inf. Syst. doi: 10.11648/j.ajomis.20180301.14

Mbunge, E. (2020a). Effects of COVID-19 in South African health system and society: An explanatory study. Diabetes Metab. Syndr. Clin. Res. Rev. doi: 10.1016/j.dsx.2020.09.016.

Mbunge, E. (2020b). Integrating emerging technologies into COVID-19 contact tracing: Opportunities, challenges and pitfalls. Diabetes Metab. Syndr. Clin. Res. Rev. doi: 10.1016/j.dsx.2020.08.029.

Mbunge, E., Akinnuwesi, B., Fashoto, S.G., Metfula, A.S. and Mashwama, P. (2020a). A critical review of emerging technologies for tackling COVID-19 pandemic. Human Behavior and Emerging Technologies. doi: 10.1002/ hbe 2.237

Mbunge, E., Fashoto, S.G., Akinnuwesi, B., Gurajena, C. and Metfula, A. (2020b). Challenges of social distancing and self-isolation during covid-19 pandemic in Africa: A critical review. SSRN Electron. J., doi: 10.2139/ssrn.3740202.

Mbunge, E., Fashoto, S.G., Akinnuwesi, B., Gurajena, C., Metfula, A. and Mashwama, P. (2020c). COVID-19 pandemic in higher education: Critical role of emerging technologies in Zimbabwe. SSRN Electron. J. doi: 10.2139/ssrn.3743246

Mbunge, E., Fashoto, S.G. and Olaomi, J. (2021). Covid-19 and online learning: factors influencing students' academic performance in first-year computer programming courses in higher education. SSRNElectron. J., Jan. doi: 10.2139/ ssrn.3757988.

Mishra, L., Gupta, T. and Shree, A. (2020). Online teaching-learning in higher education during lockdown period of COVID-19 pandemic. Int. J. Educ. Res. Open. doi: 10.1016/j.ijedro.2020.100012

Mohamed Abd El-Hamed Diab, G. and Fouad Elgahsh, N. (2020). E-learning during covid-19 pandemic: Obstacles faced nursing students and its effect on their attitudes while applying it. Am. J. Nurs. Sci. . 9(4), 300-314. doi: 10.11648/ j.ajns.20200904.33.

Ogunleye, G.O., Fashoto, S.G., Elliot, M., Arekete, S.A. and Ojewumi, T.O. (2018). Securing and monitoring of Bandwidth usage in multi-agents denial of service environment. Int. J. Adv. Comput. Sci. Appl. 9(9).

Onyema, E.M., Eucheria, N.C., Obafemi, F.A., Sen, S., Atonye, F.G., Sharma, A. and Alsayed, A.O. (2020). Impact of coronavirus pandemic on education. J. Educ. Pract., 2020, doi: 10.7176/jep/11-13-12.

Salyers, V., Carter, L., Carter, A., Myers, S. and Barrett, P. (2014). The search for meaningful e-learning at canadian universities: A multi-institutional research study. Int. Rev. Res. Open Distrib. Learn., 15(6), 313-.347

Sangrà, A., Vlachopoulos, D. and Cabrera, N. (2012). Building an inclusive definition of e-learning: An approach to the conceptual framework. Int. Rev. Res. Open Distance Learn. 13(2), 145-159. doi: 10.19173/irrodl.v13i2.1161

Siewe Fodjo, J.N. et al. (2020). Mass masking as a way to contain COVID-19 and exit lockdown in low- and middle-income countries. Journal of Infection. doi: 10.1016/j.jinf.2020.07.015.

United Nations Development Programme (UNDP) (2020a). Covid-19 and human development: Assessing the crisis, Envisioning the Recovery.

United Nations Development Programme (UNDP) (2020b). Covid-19: Human development on course to decline this year for the first time since 1990 .

Valentine, D. (2002). Distance learning: promises, problems, and possibilities. Online J. Distance Learn. Adm., 5(3).

Wise, J. (2020). Covid-19: New coronavirus variant is identified in UK. BMJ. doi: 10.1136/bmj.m4857

Cite this article as: Caroline Gurajena, Elliot M bungeand Stephen G Fashoto (2021). Teaching and learning in thenew normal: Opportunities and challenges of distance learning amid covid-19 pandemic. International Journal of Education and T eaching. 1(2), 9-15. doi: 10.51483/ IJEDT.1.2.2021.9-15. 